\title{
Phase analysis detects heterogeneity of myocardial deformation on cine MRI
}

Eva Maret, Monika Liehl, Lars Brudin, Tim Tödt, Thor Edvardsen and Jan Engvall

\author{
Linköping University Post Print
}

Tweet

N.B.: When citing this work, cite the original article.

Original Publication:

Eva Maret, Monika Liehl, Lars Brudin, Tim Tödt, Thor Edvardsen and Jan Engvall, Phase analysis detects heterogeneity of myocardial deformation on cine MRI, 2015, Scandinavian cardiovascular journal : SCJ, 1-10.

http://dx.doi.org/10.3109/14017431.2015.1023343

Copyright: Informa Healthcare

http://informahealthcare.com/

Postprint available at: Linköping University Electronic Press

http://urn.kb.se/resolve?urn=urn:nbn:se:liu:diva-115752 


\section{Phase analysis detects heterogeneity of myocardial deformation on cine MRI}

Running title: Phase identifies heterogeneous deformation

Eva Maret MD, $\mathrm{PhD}^{1,2,3}$, Monika Liehl MD ${ }^{1}$, Lars Brudin, $\mathrm{MD}, \mathrm{PhD}^{4,5}$, Tim Todt

$\mathrm{MD}, \mathrm{PhD}^{4}$, Thor Edvardsen, $\mathrm{MD}, \mathrm{PhD}^{6}$, Jan E Engvall MD, $\mathrm{PhD}^{2,4}$

${ }^{1}$ Department of Clinical Physiology, Ryhov County Hospital, SE-55185 Jonkoping,

Sweden

${ }^{2}$ Center for Medical Image Science and Visualisation, Linkoping University, SE-

58185 Linkoping

${ }^{3}$ Department of Clinical Physiology, Karolinska University Hospital, SE-14186

Stockholm, Sweden

${ }^{4}$ Department of Clinical Physiology and Department of Medical and Health Sciences, Linkoping University, SE-581 83 Linkoping, Sweden

${ }^{5}$ Department of Clinical Physiology, Kalmar County Hospital SE-39185 Kalmar,

Sweden

${ }^{5}$ Department of Cardiology, Oslo Universitetssykehus, Rikshospitalet, Postboks 4950

Nydalen, 0424 Oslo, Norway

Adress for correspondence:

Jan Engvall, MD, PhD

Department of Medical and Health Sciences

Linkoping University

SE-581 83 Linkoping, Sweden 
This is the pre peer-reviewed version of the following article, "Phase analysis detects heterogeneity of myocardial deformation on cine MRI", which in its final form has been published at Scand Cardiovasc J. 2015 Mar 10:1-24. [Epub ahead of print] PMID: 25752486.

Phone: +46-103-3314

Fax: $+46-13-145949$

E-mail: jan.engvall@lio.se

Presented in part at the Scientific meeting of the Society of Cardiovascular Magnetic

Resonance in Nice, Feb 2011. 
This is the pre peer-reviewed version of the following article, "Phase analysis detects heterogeneity of myocardial deformation on cine MRI", which in its final form has been published at Scand Cardiovasc J. 2015 Mar 10:1-24. [Epub ahead of print] PMID: 25752486.

\section{Abstract}

\section{Objectives}

Myocardial scar will lead to heterogeneous left ventricular deformation. We hypothesized that a myocardial scar will display an elevated standard deviation of phase and that this effect could be compared with mechanical dispersion.

\section{Design}

Thirty patients (3 women and 27 men) were investigated 4-8 weeks after STelevation myocardial infarction treated with percutaneous coronary intervention. Seventeen had a scar area $>75 \%$ in at least one antero- or inferoseptal segment (scar) and 13 had scar $<1 \%$ (non-scar). The phase delays of velocity, displacement and strain were measured in the longitudinal direction, tangential to the endocardial outline, and in the radial direction, perpendicular to the tangent.

\section{Results}

The standard deviation of phase in radial measurements differentiated scar patients from those without scar $(\mathrm{p}<0.01)$, while longitudinal measurements did so only for longitudinal strain. Likewise, the standard deviation for radial measurements of time to peak for segmental velocity, displacement and strain performed better than longitudinal measurements and equal to the results of phase.

\section{Conclusion}

Phase dispersion in deformation imaging may be used for detecting heterogeneous left ventricular contraction. 
This is the pre peer-reviewed version of the following article, "Phase analysis detects heterogeneity of myocardial deformation on cine MRI", which in its final form has been published at Scand Cardiovasc J. 2015 Mar 10:1-24. [Epub ahead of print] PMID: 25752486.

Key words: cardiac function tests; magnetic resonance imaging; myocardial strain; phase analysis; mechanical dispersion 
This is the pre peer-reviewed version of the following article, "Phase analysis detects heterogeneity of myocardial deformation on cine MRI", which in its final form has been published at Scand Cardiovasc J. 2015 Mar 10:1-24. [Epub ahead of print] PMID: 25752486.

\section{Introduction}

Amplitude, time to peak amplitude and phase delay are features that accurately describe the deformation pattern of the left ventricle (LV). A normal LV has been demonstrated to have homogeneous deformation (1). In a scarred LV, heterogeneous deformation due to delayed electrical activation and contractile dysfunction may be seen (2). In addition, tethering effects of segments close to the scar will also affect the deformation pattern $(1,3)$. In daily practice, deformation of the left ventricular wall is most often evaluated by visual inspection only (4). In such assessment, the human eye integrates amplitude and timing of the contracting LV segments (5). Temporal differences in the pattern of deformation may be seen as asynchronous wall motion, or, when measured in terms of velocity, displacement or strain, expressed as the standard deviation (SD) of the time to peak (TPk) value of these measurements. An increase in the temporal difference between segments has been described as “mechanical dispersion” $(2,6)$. Reduced and delayed wall deformation as a consequence of acute and chronic myocardial ischemia is known to increase the risk for arrhythmia $(2,6,7)$. Various methods have been devised to objectively detect wall motion abnormalities (8-12), but their clinical application has been limited. Phase analysis has been used in e.g. cardiac gated SPECT to assess wall motion in patients that were candidates for cardiac resynchronization therapy (CRT) (7). Phase analysis has also been applied in echocardiographic deformation imaging (13). We have previously reported on the use of a prototype feature tracking software adapted for cine MRI (2D CPA MR® - Cardiac Performance Analysis, version 1.0 b 081002 Tomtec Imaging Systems GmbH, Unterschleissheim, Germany) which also 
This is the pre peer-reviewed version of the following article, "Phase analysis detects heterogeneity of myocardial deformation on cine MRI“, which in its final form has been published at Scand Cardiovasc J. 2015 Mar 10:1-24. [Epub ahead of print] PMID: 25752486.

incorporates a phase analysis algorithm. This algorithm calculates phase delay per segment in either milliseconds (ms) or as a percentage of the cardiac cycle time, phase\%, Fig 1, Fig 2 and Fig 3 (14). Previous publications have focused on the issue of the measured parameter, whether strain, displacement or velocity. When the concept of mechanical dispersion was launched, it was natural to investigate if another measure of timing, i.e. analysis of phase, in some way could be used to obtain additional information from cine MRI.

The deformation of a cardiac wall segment can be described as a time-varying periodic function whose main timing content can be modelled by a sinusoidal wave with a phase difference in relation to other periodic functions (Fig 3). The fit between the real function and the sinusoidal model is far from perfect but may be the best representation for mathematical analysis. In the present study, we have measured the phase in scar- and non-scar patients using the first harmonic of velocity, displacement and strain which carries information from the entire RR-interval and not only from the peak of the curve. Phase\% is in this setting phase in relation to the mean deformation of the 6 segments of the slice, corrected for the duration of the RR-interval. Fig 2 depicts a sine and a cosine function with a delay of $\pi$ radians which equals $25 \%$ of the cycle time.

The aim of the present study was to assess whether the SD of phase\% of velocity, displacement and strain might detect heterogeneous left ventricular wall deformation caused by myocardial scar and to compare with analysis based on the SD of TPk. 
This is the pre peer-reviewed version of the following article, "Phase analysis detects heterogeneity of myocardial deformation on cine MRI", which in its final form has been published at Scand Cardiovasc J. 2015 Mar 10:1-24. [Epub ahead of print] PMID: 25752486.

\section{Materials and Methods}

\section{Study population}

Thirty patients ( 3 women and 27 men, age $62 \pm 11$ years, height $177 \pm 7 \mathrm{~cm}$, weight $85 \pm 11 \mathrm{~kg})$ were selected based on the presence or absence of extensive myocardial scar in anteroseptal and inferoseptal segments (15). These patients were recruited between February 2006 and September 2007 as part of a larger study assessing primary PCI for ST-elevation myocardial infarction and they agreed to return for infarct size determination with MRI 6 \pm 2 weeks after primary PCI. Seventeen patients with scar area $>75 \%$ in at least one segment (scar patients) and thirteen without scar in any part of the myocardium were selected (non-scar patients). No one had bundle branch block on resting 12-lead ECG (mean QRS duration $97 \mathrm{~ms}$ in scar patients and $92 \mathrm{~ms}$ in non-scar patients). Additional coronary stenoses not dilated at the index event were seen in 7 of the 17 scar patients and in two of the 13 non-scar patients. Three patients in the scar group had a history of previous myocardial infarction. Two of these and one patient in the non-scar group had undergone PCI earlier. None of the patients underwent CABG. Initial exclusion criteria were unwillingness to participate in the study or those related to performing MRI such as pacemaker, atrial fibrillation or claustrophobia.

The study was approved by the Regional Ethical Review Board in Linköping, Sweden, and adhered to Good Clinical Practice as set forth in the Declaration of Helsinki. Written informed consent was obtained from all patients after the nature of the procedure had been fully explained. The study was registered in the EMEA database as EudraCT 2005-001529-27. 
This is the pre peer-reviewed version of the following article, "Phase analysis detects heterogeneity of myocardial deformation on cine MRI", which in its final form has been published at Scand Cardiovasc J. 2015 Mar 10:1-24. [Epub ahead of print] PMID: 25752486.

\section{MR imaging}

Contrast enhanced cardiac MRI was performed on a Philips 1.5T Achieva Nova Dual scanner (Philips Medical Systems, Best, the Netherlands) using a five-element cardiac synergy surface coil. ECG-triggered MR images were obtained during repeated breath-holds. Cine-MR was performed with a balanced steady state free precession turbo field-echo (b-SSFP TFE) sequence and covered the entire left ventricle with on average 19 (range 17-25) short-axis and three apical long-axis slices (2-, 3- and 4chamber views). Slice thickness was $10 \mathrm{~mm}$ and slice gap $-5 \mathrm{~mm}$. Temporal resolution ranged between 26-41 ms (30 acquired phases). The contrast enhanced images were acquired at the same slice positions as the cine images, about $20 \mathrm{~min}$ after the administration of gadopentate dimeglumine (Gd-DTPA) $0.2 \mathrm{mmol} / \mathrm{kg}$ bodyweight (Schering Nordiska AB, Järfälla, Sweden). The inversion recovery turbo field echo (IR-TFE) sequence was a segmented 3D spoiled gradient echo sequence with $\mathrm{TE}=1.3 \mathrm{~ms}$, TR $=4.4 \mathrm{~ms}$ and $\mathrm{TFE}$ factor 43 , leading to an acquisition phase time of 188 ms acquired during diastole.

\section{Infarct size and transmurality}

Myocardial scar was visualized with the late gadolinium enhancement technique.

Infarct size was determined in millilitres and as a percentage of left ventricular mass from the stack of short-axis images, using “Segment”, (http://segment.heiberg.se) (16). "Segment” utilizes an algorithm that not only evaluates the signal intensity compared to a remote area, but also accounts for partial volume effects by weighting the contribution of voxels in the "gray" area surrounding the central parts of scar. The algorithm was tested in a computer model, in experimental infarction in animals and was applied to clinical patient cases (17). A scar segment was defined as any segment 
This is the pre peer-reviewed version of the following article, "Phase analysis detects heterogeneity of myocardial deformation on cine MRI", which in its final form has been published at Scand Cardiovasc J. 2015 Mar 10:1-24. [Epub ahead of print] PMID: 25752486.

with LGE positive area $\geq 1 \%$ of the segmental area. Since the main analysis of phase $\%$ and TPk was performed on long-axis cine views, the transmural extent of scar (scar area per segment and for the entire slice) was determined on long-axis slices positioned identically to those used for cine, to achieve an optimal co-registration of the data.

\section{Analysis of left ventricular size, function, phase and time-to-peak}

LV volume and ejection fraction was measured on cine loops from the short-axis orientation using View Forum ${ }^{\circledR}$ software (Philips Healthcare, Eindhoven, the Netherlands). Velocity, displacement and strain of left ventricular segments as well as segmental time to peak and phase delay was determined with the 2D-CPA-MR software from DICOM images recorded in the long-axis view and converted to avifiles. The left ventricular endocardium and epicardium was outlined manually in diastole, followed by software tracking of the deformation of the wall throughout the cardiac cycle (18). The left ventricular myocardium was divided into 6 segments in each of the three long-axis views, giving a total of 18 segments (6 in each level, basemid-apex). The tracing of the myocardium was repeated three times and the mean value of the SD of phase\% and TPk was used. Velocity, displacement and strain was calculated tangential to the endocardial outline, ("longitudinal”), and perpendicular to the tangent, ("radial”). The segmental delay time of the peak value was displayed for each of the six segments per long-axis view (blue boxes of Fig 1). The average SD of phase\% was computed for each apical view. Since the three views of each patient are independent, the root sum square (RSS) of the SD of phase\% was calculated per subject, and compared with the RSS of the SD of TPk. 
This is the pre peer-reviewed version of the following article, "Phase analysis detects heterogeneity of myocardial deformation on cine MRI", which in its final form has been published at Scand Cardiovasc J. 2015 Mar 10:1-24. [Epub ahead of print] PMID: 25752486.

\section{Reproducibility}

The long-axis recordings of 10 patients ( 5 scar, 5 non-scar) were analysed by two independent observers performing three repeated segmentations on three views. For intraobserver analysis, three measurements on three views were available for all 30 patients (180 data points). Analysis of short-axis recordings were done only for comparison of reproducibility and based on three repeated measurements of three short-axis slices (one for each level base-mid-apex) from 5 scar and 5 non-scar patients, by two observers.

\section{Statistical analysis}

Statistical analyses were performed using SPSS 16.0 (SPSS Inc., Chicago, Illinois, USA) as well as Statistica 8.0 (Statsoft Inc, Tulsa, Oklarhoma, USA). The variables did not deviate from normality, allowing parametric tests to be used. Paired and unpaired 2-tailed Student's t-tests were used along with ANOVA (followed by Duncan's test in case of significance). Receiver-operator-characteristic (ROC) curves were constructed using MedCalc® Version 6.10 (MedCalc Software, Mariakerke, Belgium). Intra- and interobserver variability of phase $\%$ and $\mathrm{TPk}$ was expressed according to Dahlberg (19) and Bland-Altman (20) and as intraclass correlation coefficient, ICC.

\section{Results}

\section{Left ventricular scar size, volume and LVEF}

In scar patients, the size of the scar was on average $31 \pm 12 \mathrm{ml}$ or $17 \pm 8 \%$ of the left ventricular myocardium. Left ventricular end-diastolic volumes (LVEDV) and end- 
This is the pre peer-reviewed version of the following article, "Phase analysis detects heterogeneity of myocardial deformation on cine MRI", which in its final form has been published at Scand Cardiovasc J. 2015 Mar 10:1-24. [Epub ahead of print] PMID: 25752486.

systolic volumes (LVESV) were significantly larger and left ventricular ejection fraction (LVEF) lower in the scar group compared with the non-scar group (Table 1).

\section{Scar area per view and per segment}

In the scar group, scar area was $29.9 \pm 9.9 \%$ (range $7-45 \%$ ) in the 4 -chamber view, $37.5 \pm 10.4 \%$ (range $13-51 \%$ ) and $35.3 \pm 8.8 \%$ (range $19-48 \%$ ) in the 2 -chamber and in the 3-chamber views, respectively. Expressed per segment, scar area exceeded 50\% in $35 \%$ of the segments of the scar patients (Table 1). Significant gadolinium uptake was not seen in the non-scar group.

\section{Difference in phase\% between scar and non-scar patients}

The average SD of phase\% per view as well as total RSS_SD-phase\% per subject is shown in Fig 4, left panels. In the radial direction, average SD for phase\% was significantly higher for scar vs. non-scar for velocity, displacement and strain in all views except for strain in the apical 4-chamber view, ( $p<0.001$ for all). Average SD for phase\% in the longitudinal direction showed no difference between scar and nonscar for velocity and displacement but was significant for strain in the apical 2-and 3chamber views.

RSS_SD-phase\% in the radial direction (three apical views per subject taken together) was significantly higher for scar vs. non-scar patients ( $p<0.001$ for velocity and displacement, $\mathrm{p}<0.01$ for strain). RSS_SD-phase\% in the longitudinal direction was significant only for strain $(\mathrm{p}<0.01)$, Fig 4 . Using a cut-off of 5.2\% of RSS_SDphase $\%$ of radial strain identified scar patients with $76 \%$ sensitivity and $100 \%$ 
This is the pre peer-reviewed version of the following article, "Phase analysis detects heterogeneity of myocardial deformation on cine MRI", which in its final form has been published at Scand Cardiovasc J. 2015 Mar 10:1-24. [Epub ahead of print] PMID: 25752486.

specificity. The RSS_SD-phase\% for radial velocity, displacement and strain all correlated with the size of myocardial scar (strain is shown in Fig 5).

\section{Difference in TPk between scar and non-scar patients}

The SD of TPk for velocity, displacement and strain in the radial direction (RSS, composite of all three views) was for scar patients 103, 95 and 85 ms and for non-scar patients 44, 39 and 36 ms respectively, Fig 4. This difference was significant for all three measures, but in the longitudinal direction, only strain displayed a statistically significant difference between scar and non-scar patients.

Using a cut-off of 50ms for the RSS-SD-TPk of radial strain, as suggested for echocardiographic longitudinal strain by Haugaa et al (2), identified scar patients with 85\% sensitivity and $92 \%$ specificity.

\section{ROC-analysis of phase $\%$ and TPk for the detection of myocardial scar}

Displacement, velocity and strain are all interconnected and in this study based on the same segmentation and tracking session. In univariate analysis, SD of phase $\%$ and SD of TPk for velocity and strain in the radial direction performed best. All four had values for area-under-curve (AUC) $>0.9$ for the detection of scarred segments. In de Long pairwise testing, the difference in AUC was not significant for any of the four measures. The best value was obtained for radial velocity with AUCtpk-sd 0.95 and AUCphase-sd 0.97, Fig 6.

\section{Intra observer variability}


This is the pre peer-reviewed version of the following article, "Phase analysis detects heterogeneity of myocardial deformation on cine MRI", which in its final form has been published at Scand Cardiovasc J. 2015 Mar 10:1-24. [Epub ahead of print] PMID: 25752486.

Intraobserver variability, based on all 30 patients, 3 views and 3 measurements (intra_SD for long axis segmentation, Table 2) was expressed as the coefficient of variation (COV) of a single determination calculated from two successive differences according to Dahlberg (19). This figure was lowest for radial velocity and radial displacement (24\% and 23\%) but higher in the longitudinal direction and for radial and longitudinal strain.

Since the three views constitute independent samples, the root-sum-square was also calculated (intra_RSS), which had a COV of 16-18\% for velocity and displacement, and $25 \%$ for strain, Table 2 .

For comparison, intra-SD for short axis measurements of strain only (10 patients, 3 slices, 3 measurements, 2 observers) showed radial COV 44\% and circumferential COV 62\%. Intra-RSS was higher than for long axis segmentations, radial COV being 32\% and circumferential 36\%.

\section{Interobserver variability}

Interobserver variability of phase\%, determined from an average of three measurements for each observer (inter-SD for the long axis in Table 2), showed little difference between radial vs longitudinal measurements: COV $17 \%$ for both radial velocity and displacement while radial strain had higher COV $44 \%$ than longitudinal strain which had COV 22\%, Table 2. Interobserver variability showed no apparent difference between smaller and larger absolute values, as can be seen from the BlandAltmann plot of Fig 7. 
This is the pre peer-reviewed version of the following article, "Phase analysis detects heterogeneity of myocardial deformation on cine MRI", which in its final form has been published at Scand Cardiovasc J. 2015 Mar 10:1-24. [Epub ahead of print] PMID: 25752486.

In short-axis segmentations, inter_SD had radial COV of $47 \%$ and circumferential COV 49\% (Table 2).

All measurements have also been calculated as intraclass correlation coefficients and according to Dahlberg (19) in Table 2.

Bland_Altman diagrams were created but are only shown for strain (Figure 7. Intraobserver variability has identical limits of agreement for long-axis segmentation (upper two panels) and short-axis segmentation (lower two panels). Interobserver Bland-Altman was calculated for the apical 2-chamber view to illustrate the effect of averaging three measurements, which had about half the limit of agreement as the individual measurements (middle panels).

\section{Discussion}

The focus in deformation imaging has been on the size of the measurement, regardless if it has been obtained from tissue Doppler, speckle tracking echocardiography or tagging MRI. This is the first study to evaluate phase differences obtained from deformation as the basis for detecting myocardial scar. The deformation of a myocardial segment is a complicated summation of shortening in the fibre direction, cross-fibre shortening, the interaction of fibres of different angles and effects of the extracellular matrix (21-23). We found a very low phase difference in hearts without scar indicating homogeneous deformation (Fig 4). In patients with scar, the difference in the SD of phase\% in the radial direction increased three-fold and in the SD of TPk two-fold, possibly due to postsystolic shortening $(24,25)$ or early systolic lengthening (26). An increased phase difference as detected in our study, expresses 
This is the pre peer-reviewed version of the following article, "Phase analysis detects heterogeneity of myocardial deformation on cine MRI“, which in its final form has been published at Scand Cardiovasc J. 2015 Mar 10:1-24. [Epub ahead of print] PMID: 25752486.

heterogeneous contraction, which previously has been connected with an increased risk of malignant arrhythmia $(2,27,28)$. Analysis of phase from plain cine MRI may thus add an objective measure and improve the large intra- and interobserver variation of visual assessment that has been documented for MRI (29) as well as for echocardiography (30).

Speckle tracking in echocardiography tracks the longitudinal direction better than the radial, possibly due to a low lateral resolution (31). The 2D-CPA-MR software used in this study showed COV for phase\% that was similar in both the radial and in the longitudinal directions. However, in terms of ICC, the radial direction had lower variability. Hypothetically, the large contrast between the myocardium and the signal from blood in the ventricular cavity facilitates 1D-tracking perpendicular to the outline of the endocardium, as explained by Hor et al (18) while tracking longitudinal deformation relies on detecting features in the myocardium analogous to echocardiographic speckles (“2D-tracking”). Nevertheless, even if reproducibility is important, the ability to discriminate between scar and non-scar patients is the final clinical test. In that respect, phase displayed a larger difference between scar and nonscar individuals than time to peak. Furthermore, even if COV was lowest for velocity and displacement, strain was the only parameter that could separate scar from nonscar in the longitudinal direction.

Despite several limitations in the present study, 5.2\% of RSS-SD-phase\% of radial strain identified patients with scar with $76 \%$ sensitivity and $100 \%$ specificity. Using analysis of time-to-peak, a cut-off of RSS-SD-TPk of $50 \mathrm{~ms}$ for radial strain had 85\% sensitivity and $92 \%$ specificity for the detection of scar patients. We have previously 
This is the pre peer-reviewed version of the following article, "Phase analysis detects heterogeneity of myocardial deformation on cine MRI“, which in its final form has been published at Scand Cardiovasc J. 2015 Mar 10:1-24. [Epub ahead of print] PMID: 25752486.

shown that measurements of velocity, displacement and peak systolic strain in the radial direction by MRI were able to differentiate segments with varying extent of scar (14). The most accurate information was obtained by measurements of radial strain in that study. In the present patient based analysis, phase\% or TPk of radial velocity and strain performed equally in the identification of scar. Future studies should investigate if phase analysis could add important information about the propensity for life threatening arrythmia in patients at risk or possibly give additional information if added to a composite measure of amplitude and timing of deformation.

\section{Reproducibility}

Previous publications have been concerned with the reproducibility of feature tracking (32). Based on the reproducibility of data obtained from healthy volunteers, Morton et al recommended the use of circumferential strain which had a lower coefficient of variation than longitudinal or radial strain. In the present patient cohort, we could not confirm this advantage of circumferential measurements for the analysis of phase, neither when using single determinations nor when using an average of three tracings. Our data show that averaging three measurements as expected reduces variability (Table 2), in line with a current publication on the use of feature tracking for atrial function (33).

\section{Limitations}

This study was performed as proof of concept on a small number of patients. The analysis of phase or time-to-peak needs to be applied also on scar patients with different degrees of transmurality and preferably in larger patient samples since the 
This is the pre peer-reviewed version of the following article, "Phase analysis detects heterogeneity of myocardial deformation on cine MRI“, which in its final form has been published at Scand Cardiovasc J. 2015 Mar 10:1-24. [Epub ahead of print] PMID: 25752486.

phase $\%$ of wall deformation in patients with subendocardial scar might be different from those with transmural scar. Additionally, extensive scar within one slice could possibly lead to similar phase delays in several segments effectively eliminating any differences in phase\% between segments. In a comparison of measurements derived from the short-axis compared to the long-axis we chose to use coefficient of variation of the individual measurements, but a complete ROC analysis would have been preferable. Furthermore, the temporal resolution of MRI cine is of concern. Echocardiographic speckle tracking accepts temporal resolution as low as $38 \mathrm{fps}$ which is within the range achieved with this time averaged cine CMR. We therefore believe that the temporal resolution in our study apparently is sufficient for detecting temporal dispersion with strain and displacement while the highest velocities might be missed. Lastly, some patients had additional stenoses that were not dilated at primary PCI. We found it unlikely that they would have caused stunning and additional phase delay since the patients were free from symptoms of ischemia.

\section{Conclusions}

MRI feature tracking with phase analysis is able to detect heterogeneous myocardial deformation which closely follows the presence of transmural scar. Further studies are needed for determining the predictive value of this finding as an indicator of the risk for malignant arrhythmia in individual patients. 
This is the pre peer-reviewed version of the following article, "Phase analysis detects heterogeneity of myocardial deformation on cine MRI", which in its final form has been published at Scand Cardiovasc J. 2015 Mar 10:1-24. [Epub ahead of print] PMID: 25752486.

\section{Acknowledgements}

Johan Kihlberg, RN, and the MRI-technicians at CMIV are gratefully acknowledged for scanning the patients and Elisabeth Logander, RN, for coordinating patient recruitment. Professor Gianni Pedrizzetti, University of Trieste, and Rolf Baumann, chief technology officer of Tomtec, provided fruitful discussions on issues regarding phase.

\section{Funding}

Futurum - the Academy for healthcare, Jonkoping County Council [grant 5339], the Swedish Heart Lung Foundation [grant 20120449], the Medical Research Council of Southeast Sweden [grant 4138] and CMIV, Linkoping University.

\section{Financial disclosures}

None 
This is the pre peer-reviewed version of the following article, "Phase analysis detects heterogeneity of myocardial deformation on cine MRI", which in its final form has been published at Scand Cardiovasc J. 2015 Mar 10:1-24. [Epub ahead of print] PMID: 25752486.

\section{References}

1. Edvardsen T, Gerber BL, Garot J, Bluemke DA, Lima JA, Smiseth OA. Quantitative assessment of intrinsic regional myocardial deformation by Doppler strain rate echocardiography in humans: validation against three-dimensional tagged magnetic resonance imaging. Circulation. 2002 Jul 2;106(1):50-6. PubMed PMID: 12093769. Epub 2002/07/03. eng.

2. Haugaa KH, Smedsrud MK, Steen T, Kongsgaard E, Loennechen JP, Skjaerpe $\mathrm{T}$, et al. Mechanical dispersion assessed by myocardial strain in patients after myocardial infarction for risk prediction of ventricular arrhythmia. JACC CardiovasC Imaging. 2010 Mar;3(3):247-56. PubMed PMID: 20223421. Epub 2010/03/13. eng.

3. Force T, Kemper A, Perkins L, Gilfoil M, Cohen C, Parisi AF. Overestimation of infarct size by quantitative two-dimensional echocardiography: the role of tethering and of analytic procedures. Circulation. 1986 Jun;73(6):1360-8. PubMed PMID: 3698262.

4. Blondheim DS, Beeri R, Feinberg MS, Vaturi M, Shimoni S, Fehske W, et al. Reliability of visual assessment of global and segmental left ventricular function: a multicenter study by the Israeli Echocardiography Research Group. J Am Soc Echocardiogr. 2010 Mar;23(3):258-64. PubMed PMID: 20138473. Epub 2010/02/09. eng.

5. Kvitting JP, Wigstrom L, Strotmann JM, Sutherland GR. How accurate is visual assessment of synchronicity in myocardial motion? An In vitro study with computer-simulated regional delay in myocardial motion: clinical implications for rest 
This is the pre peer-reviewed version of the following article, "Phase analysis detects heterogeneity of myocardial deformation on cine MRI", which in its final form has been published at Scand Cardiovasc J. 2015 Mar 10:1-24. [Epub ahead of print] PMID: 25752486.

and stress echocardiography studies. J Am Soc Echocardiogr. 1999 Sep;12(9):698705. PubMed PMID: 10477413. Epub 1999/09/08. eng.

6. Nagueh SF. Mechanical dyssynchrony in congestive heart failure: diagnostic and therapeutic implications. J Am Coll Cardiol. 2008 Jan 1;51(1):18-22. PubMed PMID: 18174031. Epub 2008/01/05. eng.

7. Atchley AE, Trimble MA, Samad Z, Shaw LK, Pagnanelli R, Chen J, et al. Use of phase analysis of gated SPECT perfusion imaging to quantify dyssynchrony in patients with mild-to-moderate left ventricular dysfunction. J Nucl Cardiol. 2009 Nov-Dec;16(6):888-94. PubMed PMID: 19690935. Epub 2009/08/20. eng.

8. Amundsen BH, Crosby J, Steen PA, Torp H, Slordahl SA, Stoylen A. Regional myocardial long-axis strain and strain rate measured by different tissue Doppler and speckle tracking echocardiography methods: a comparison with tagged magnetic resonance imaging. Eur J Echocardiogr. 2009;10(2):229-37. PubMed PMID: 18650220.

9. D'Hooge J, Heimdal A, Jamal F, Kukulski T, Bijnens B, Rademakers F, et al. Regional strain and strain rate measurements by cardiac ultrasound: principles, implementation and limitations. Eur J Echocardiogr. 2000 Sep;1(3):154-70. PubMed PMID: 11916589.

10. Madler CF, Payne N, Wilkenshoff U, Cohen A, Derumeaux GA, Pierard LA, et al. Non-invasive diagnosis of coronary artery disease by quantitative stress echocardiography: optimal diagnostic models using off-line tissue Doppler in the MYDISE study. Eur Heart J. 2003 Sep;24(17):1584-94. PubMed PMID: 12927194. Epub 2003/08/21. eng. 
This is the pre peer-reviewed version of the following article, "Phase analysis detects heterogeneity of myocardial deformation on cine MRI", which in its final form has been published at Scand Cardiovasc J. 2015 Mar 10:1-24. [Epub ahead of print] PMID: 25752486.

11. Osman NF, Prince JL. Regenerating MR tagged images using harmonic phase (HARP) methods. IEEE Trans Biomed Eng. 2004 Aug;51(8):1428-33. PubMed PMID: 15311829.

12. Ryf S, Spiegel MA, Gerber M, Boesiger P. Myocardial tagging with 3DCSPAMM. J Magn Reson Imaging. 2002 Sep;16(3):320-5. PubMed PMID: 12205589.

13. Breithardt OA, Stellbrink C, Kramer AP, Sinha AM, Franke A, Salo R, et al. Echocardiographic quantification of left ventricular asynchrony predicts an acute hemodynamic benefit of cardiac resynchronization therapy. J Am Coll Cardiol. 2002 Aug 7;40(3):536-45. PubMed PMID: 12142123. Epub 2002/07/27. eng.

14. Maret E, Todt T, Brudin L, Nylander E, Swahn E, Ohlsson JL, et al. Functional measurements based on feature tracking of cine magnetic resonance images identify left ventricular segments with myocardial scar. Cardiovasc Ultrasound. 2009;7:53. PubMed PMID: 19917130. Epub 2009/11/18. eng.

15. Cerqueira MD, Weissman NJ, Dilsizian V, Jacobs AK, Kaul S, Laskey WK, et al. Standardized myocardial segmentation and nomenclature for tomographic imaging of the heart: a statement for healthcare professionals from the Cardiac Imaging Committee of the Council on Clinical Cardiology of the American Heart Association. Circulation. 2002 Jan 29;105(4):539-42. PubMed PMID: 11815441. Epub 2002/01/30. eng.

16. Heiberg E, Sjogren J, Ugander M, Carlsson M, Engblom H, Arheden H. Design and validation of Segment--freely available software for cardiovascular image analysis. BMC Med Imaging. 2010;10:1. PubMed PMID: 20064248. Epub 2010/01/13. eng. 
This is the pre peer-reviewed version of the following article, "Phase analysis detects heterogeneity of myocardial deformation on cine MRI", which in its final form has been published at Scand Cardiovasc J. 2015 Mar 10:1-24. [Epub ahead of print] PMID: 25752486.

17. Heiberg E, Ugander M, Engblom H, Gotberg M, Olivecrona GK, Erlinge D, et al. Automated quantification of myocardial infarction from MR images by accounting for partial volume effects: animal, phantom, and human study. Radiology. 2008 Feb;246(2):581-8. PubMed PMID: 18055873.

18. Hor KN, Baumann R, Pedrizzetti G, Tonti G, Gottliebson WM, Taylor M, et al. Magnetic resonance derived myocardial strain assessment using feature tracking. Journal of visualized experiments : JoVE. 2011 (48). PubMed PMID: 21372778. Pubmed Central PMCID: 3074463.

19. Dahlberg G. Statistical methods for medical and biological students. 2nd edn ed. London: George Allen \& Unwin Ltd; 19401940.

20. Bland JM, Altman DG. Statistical methods for assessing agreement between two methods of clinical measurement. Lancet. 1986 Feb 8;1(8476):307-10. PubMed PMID: 2868172.

21. MacGowan GA, Shapiro EP, Azhari H, Siu CO, Hees PS, Hutchins GM, et al. Noninvasive measurement of shortening in the fiber and cross-fiber directions in the normal human left ventricle and in idiopathic dilated cardiomyopathy. Circulation. 1997 Jul 15;96(2):535-41. PubMed PMID: 9244222. Epub 1997/07/15. eng.

22. Sallin EA. Fiber orientation and ejection fraction in the human left ventricle. Biophys J. 1969 Jul;9(7):954-64. PubMed PMID: 5791550. Epub 1969/07/01. eng.

23. Tseng WY, Reese TG, Weisskoff RM, Brady TJ, Wedeen VJ. Myocardial fiber shortening in humans: initial results of MR imaging. Radiology. 2000 Jul;216(1):128-39. PubMed PMID: 10887238. Epub 2000/07/11. eng.

24. Celutkiene J, Sutherland GR, Laucevicius A, Zakarkaite D, Rudys A, Grabauskiene V. Is post-systolic motion the optimal ultrasound parameter to detect 
This is the pre peer-reviewed version of the following article, "Phase analysis detects heterogeneity of myocardial deformation on cine MRI", which in its final form has been published at Scand Cardiovasc J. 2015 Mar 10:1-24. [Epub ahead of print] PMID: 25752486.

induced ischaemia during dobutamine stress echocardiography? Eur Heart J. 2004 Jun;25(11):932-42. PubMed PMID: 15172465. Epub 2004/06/03. eng.

25. Ryf S, Rutz AK, Boesiger P, Schwitter J. Is post-systolic shortening a reliable indicator of myocardial viability? An MR tagging and late-enhancement study. Journal of cardiovascular magnetic resonance : official journal of the Society for Cardiovascular Magnetic Resonance. 2006;8(3):445-51. PubMed PMID: 16755830.

26. Zahid W, Eek CH, Remme EW, Skulstad H, Fosse E, Edvardsen T. Early systolic lengthening may identify minimal myocardial damage in patients with nonST-elevation acute coronary syndrome. European heart journal cardiovascular Imaging. 2014 May 27. PubMed PMID: 24866900.

27. Haugaa KH, Amlie JP, Berge KE, Leren TP, Smiseth OA, Edvardsen T. Transmural differences in myocardial contraction in long-QT syndrome: mechanical consequences of ion channel dysfunction. Circulation. 2010 Oct 5;122(14):1355-63. PubMed PMID: 20855658. Epub 2010/09/22. eng.

28. Sarvari SI, Haugaa KH, Anfinsen OG, Leren TP, Smiseth OA, Kongsgaard E, et al. Right ventricular mechanical dispersion is related to malignant arrhythmias: a study of patients with arrhythmogenic right ventricular cardiomyopathy and subclinical right ventricular dysfunction. Eur Heart J. 2011 May;32(9):1089-96. PubMed PMID: 21406439. Epub 2011/03/17. eng.

29. Paetsch I, Jahnke C, Ferrari VA, Rademakers FE, Pellikka PA, Hundley WG, et al. Determination of interobserver variability for identifying inducible left ventricular wall motion abnormalities during dobutamine stress magnetic resonance imaging. Eur Heart J. 2006 Jun;27(12):1459-64. PubMed PMID: 16613929. 
This is the pre peer-reviewed version of the following article, "Phase analysis detects heterogeneity of myocardial deformation on cine MRI", which in its final form has been published at Scand Cardiovasc J. 2015 Mar 10:1-24. [Epub ahead of print] PMID: 25752486.

30. Hoffmann R, Lethen H, Marwick T, Arnese M, Fioretti P, Pingitore A, et al. Analysis of interinstitutional observer agreement in interpretation of dobutamine stress echocardiograms. J Am Coll Cardiol. 1996 Feb;27(2):330-6. PubMed PMID: 8557902. Epub 1996/02/01. eng.

31. Amundsen BH, Helle-Valle T, Edvardsen T, Torp H, Crosby J, Lyseggen E, et al. Noninvasive myocardial strain measurement by speckle tracking echocardiography: validation against sonomicrometry and tagged magnetic resonance imaging. J Am Coll Cardiol. 2006 Feb 21;47(4):789-93. PubMed PMID: 16487846.

32. Morton G, Schuster A, Jogiya R, Kutty S, Beerbaum P, Nagel E. Inter-study reproducibility of cardiovascular magnetic resonance myocardial feature tracking. Journal of cardiovascular magnetic resonance : official journal of the Society for Cardiovascular Magnetic Resonance. 2012;14:43. PubMed PMID: 22721175. Pubmed Central PMCID: 3461471.

33. Kowallick JT, Kutty S, Edelmann F, Chiribiri A, Villa A, Steinmetz M, et al. Quantification of left atrial strain and strain rate using Cardiovascular Magnetic Resonance myocardial feature tracking: a feasibility study. Journal of Cardiovascular Magnetic Resonance. 2014;16(60). Epub 12/08/2014. 
This is the pre peer-reviewed version of the following article, "Phase analysis detects heterogeneity of myocardial deformation on cine MRI", which in its final form has been published at Scand Cardiovasc J. 2015 Mar 10:1-24. [Epub ahead of print] PMID: 25752486.

\section{Tables}

Table 1. Cardiac function and scar size

$\begin{array}{ccc}\text { Scar } & \text { Non-scar } & \mathbf{p} \\ (\mathrm{n}=17) & (\mathrm{n}=13)\end{array}$

Cine-MRI

$\begin{array}{lccc}\text { LVEDV,ml } & 160 \pm 42(102-269) & 137 \pm 16(115-170) & 0.049 \\ \text { LVESV,ml } & 99 \pm 35(51-188) & 55 \pm 16(25-90) & 0.0001 \\ \text { LVEF,\% } & 39 \pm 9(19-53) & 60 \pm 8(47-78) & <0.0001\end{array}$

\section{LGE-MRI}

\begin{tabular}{|c|c|c|}
\hline LVmass,g & $190 \pm 37(151-266)$ & $154 \pm 25(110-180)$ \\
\hline LVscar,\% & $16.6 \pm 8.4(1-35)$ & $0.2 \pm 0.4(0-1)$ \\
\hline Transmurality & $\mathrm{nr}$ of segments (\%) & $\mathrm{nr}$ of segments (\%) \\
\hline $1-25 \%$ & $36(12)$ & 0 \\
\hline $26-50 \%$ & $22(7)$ & 0 \\
\hline $51-75 \%$ & $29(9)$ & 0 \\
\hline $76-100 \%$ & $78(26)$ & 0 \\
\hline
\end{tabular}

Legend: Left ventricular volumes, left ventricular mass and transmurality of scar for the two patient categories. 
This is the pre peer-reviewed version of the following article, "Phase analysis detects heterogeneity of myocardial deformation on cine MRI", which in its final form has been published at Scand Cardiovasc J. 2015 Mar 10:1-24. [Epub ahead of print] PMID: 25752486.

Table 2. Intra- and interobserver variability from the long- and short-axis views

\begin{tabular}{|c|c|c|c|c|c|c|}
\hline & \multicolumn{6}{|c|}{ Long axis segmentation } \\
\hline & \multicolumn{3}{|c|}{ Radial } & \multicolumn{3}{|c|}{ Longitudinal } \\
\hline & ICC & Smethod & COV\% & ICC & Smethod & Cov\% \\
\hline \multicolumn{7}{|l|}{ Strain } \\
\hline Intra_SD & 0.85 & 2.3 & 47 & 0.63 & 3.4 & 39 \\
\hline Intra_RSS & 0.93 & 2.4 & 25 & 0.72 & 4.1 & 25 \\
\hline Inter_SD & 0.66 & 1.0 & 44 & 0.87 & 1.8 & 22 \\
\hline \multicolumn{7}{|l|}{ Velocity } \\
\hline Intra_SD & 0.92 & 1.4 & 24 & 0.63 & 4.3 & 33 \\
\hline Intra_RSS & 0.95 & 1.7 & 16 & 0.73 & 4.2 & 17 \\
\hline Inter_SD & 0.97 & 0.6 & 17 & 0.85 & 2.5 & 17 \\
\hline \multicolumn{7}{|l|}{ Displacement } \\
\hline Intra_SD & 0.92 & 1.4 & 23 & 0.64 & 4.3 & 34 \\
\hline Intra_RSS & 0.95 & 1.7 & 16 & 0.77 & 4.3 & 18 \\
\hline \multirow[t]{4}{*}{ Inter_SD } & 0.97 & 0.6 & 17 & 0.83 & 2.8 & 20 \\
\hline & \multicolumn{6}{|c|}{ Short axis segmentation } \\
\hline & \multicolumn{3}{|c|}{ Radial } & \multicolumn{3}{|c|}{ Circumferential } \\
\hline & ICC & Smethod & COV\% & ICC & Smethod & cov\% \\
\hline \multicolumn{7}{|l|}{ Strain } \\
\hline Intra_SD & 0.76 & 2.8 & 44 & 0.45 & 3.5 & 62 \\
\hline Intra_RSS & 0.76 & 3.9 & 32 & 0.46 & 4.1 & 36 \\
\hline Inter_SD & 0.77 & 2.5 & 47 & 0.59 & 2.4 & 49 \\
\hline Inter_RSS & 0.84 & 3.0 & 28 & 0.51 & 3.6 & 37 \\
\hline
\end{tabular}

Legend: Intra- and interobserver variability. For the long axis, strain, velocity and displacement in the radial and longitudinal directions are displayed. Intraclass correlation coefficients and coefficients of variation have been calculated as well as single determinations according to Dahlberg(19). 
This is the pre peer-reviewed version of the following article, "Phase analysis detects heterogeneity of myocardial deformation on cine MRI", which in its final form has been published at Scand Cardiovasc J. 2015 Mar 10:1-24. [Epub ahead of print] PMID: 25752486.

\section{Legends to Figures}

Figure 1: Viewport with strain curves from a patient with anteroapical infarction.

Radial strain upper right and longitudinal strain lower right. Blue fields to the left display segmental values and green horse-shoes in the middle phase per segment.

Figure 2: Principle of phase delay. The sine function is identical to the cosine function but delayed by $\pi / 2$, or $25 \%$ of the cycle length.

Figure 3: Enlargement of the 6 strain curves of the patient in Figure 1 (above), with their respective phase curves (below). Image courtesy of professor Gianni Pedrizetti.

Figure 4: Graphical display of the standard deviation of phase and time-to-peak in patients with and without myocardial scar. Left: Phase\% delay, average SD for 3 apical views and root-sum-square per patient for strain (upper), velocity (middle) and displacement (lower panel). Radial measurements left, longitudinal right. Slashed bars denote scar patients, solid black bars denote patients without scar. Right: Average SD for TPk and RSS-SD-TPk for the same measurements.

Fig 5: The relationship between radial strain RSS-SD-phase\% and scar volume. The correlation is $\mathrm{y}=3.399+0.507 * \mathrm{x} ; \mathrm{r}=0.660$

Figure 6: Area under curve for the detection of scar in a patient based analysis using RSS-SD-phase\% for radial strain (Ph_rad_strain_SD, AUC=0.9) and radial velocity (Ph_Rad_Vel_SD, AUC=0.968) compared with RSS-SD-TPk for radial strain 
This is the pre peer-reviewed version of the following article, "Phase analysis detects heterogeneity of myocardial deformation on cine MRI", which in its final form has been published at Scand Cardiovasc J. 2015 Mar 10:1-24. [Epub ahead of print] PMID: 25752486.

(TPK_Rad_Strain_SD, AUC=0.959) and radial velocity (TPK_Rad_Vel_SD, AUC=0.95). There is no significant difference between the four curves, when analysed according to DeLong.

Figure 7: Upper two panels display intraobserver variability of phase\% based on the difference between measurement 1-2 and 1-3 in three apical views of 30 patients (180 pairs). Radial strain to the left, longitudinal strain to the right. Middle two panels show interobserver variability between two observers using the mean of their three measurements in the apical 2Ch view. Radial to the left, longitudinal to the right. Lower panels display intraobserver variability using three measurements on three slices from 10 patients, obtained in the shortaxis view (60 pairs). Values are displayed according to Bland-Altman. 
This is the pre peer-reviewed version of the following article, "Phase analysis detects heterogeneity of myocardial deformation on cine MRI", which in its final form has been published at Scand Cardiovasc J. 2015 Mar 10:1-24. [Epub ahead of print] PMID: 25752486.

\section{Figures}

Figure 1. Viewport with strain curves from a patient with an anterior infarction

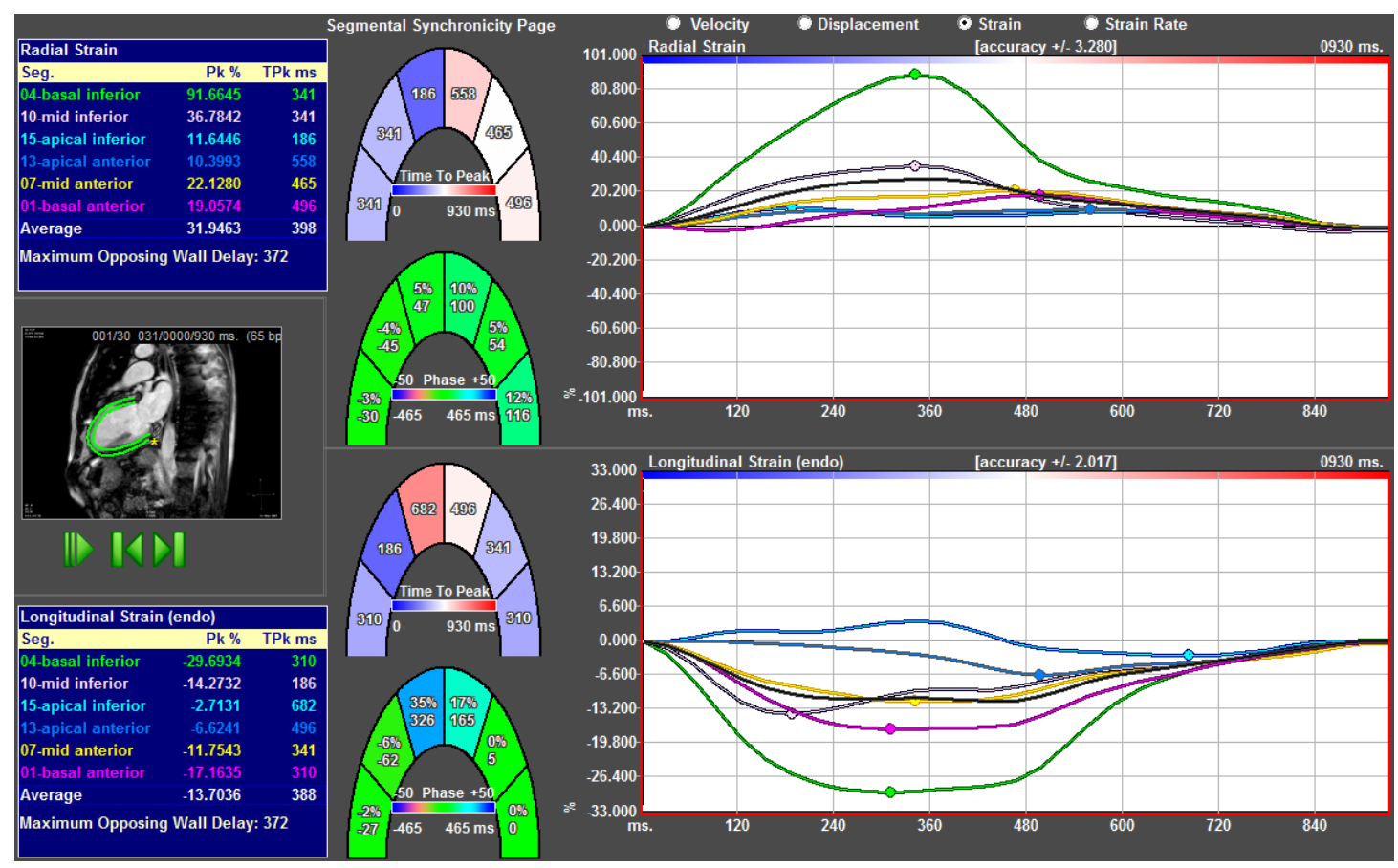


This is the pre peer-reviewed version of the following article, "Phase analysis detects heterogeneity of myocardial deformation on cine MRI", which in its final form has been published at Scand Cardiovasc J. 2015 Mar 10:1-24. [Epub ahead of print] PMID: 25752486.

Figure 2. Principle of phase delay

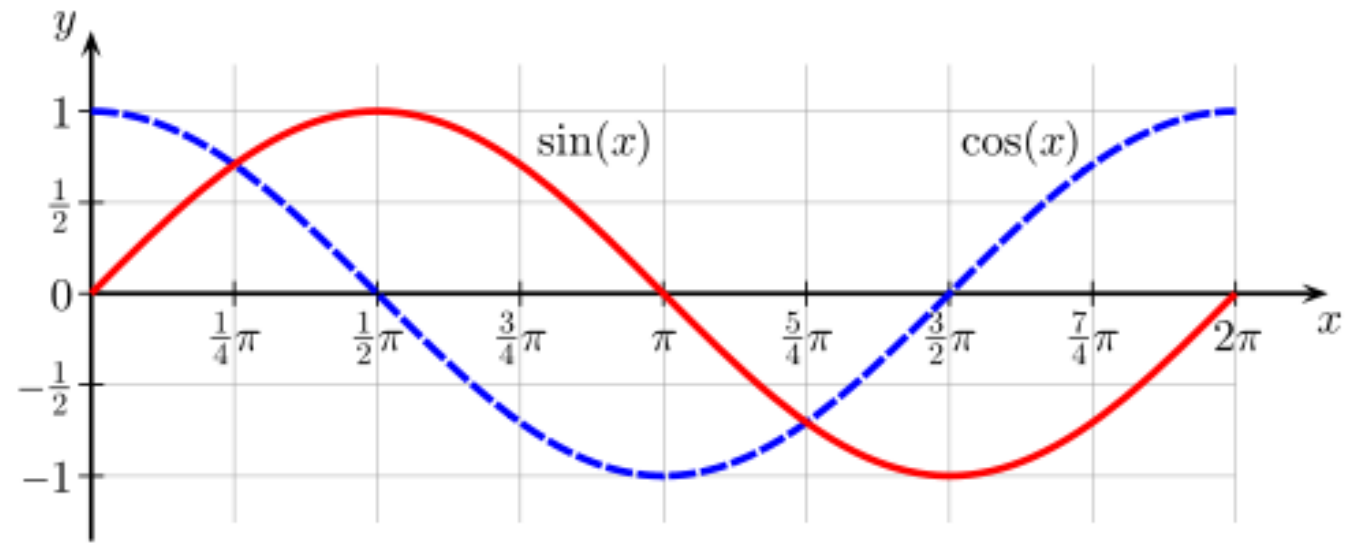


This is the pre peer-reviewed version of the following article, "Phase analysis detects heterogeneity of myocardial deformation on cine MRI", which in its final form has been published at Scand Cardiovasc J. 2015 Mar 10:1-24. [Epub ahead of print] PMID: 25752486.

Figure 3. Longitudinal strain curves and their corresponding phase curves
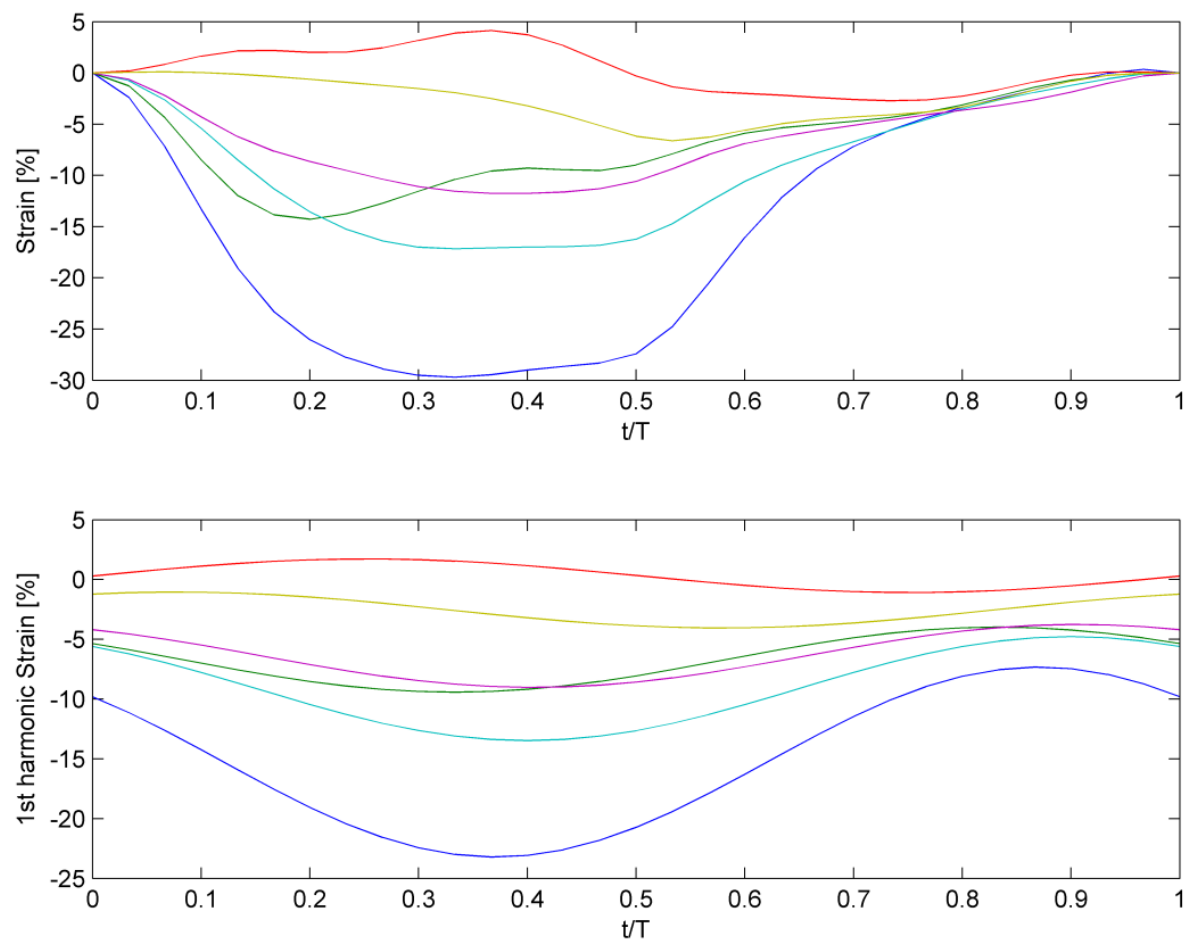
This is the pre peer-reviewed version of the following article, "Phase analysis detects heterogeneity of myocardial deformation on cine MRI", which in its final form has been published at Scand Cardiovasc J. 2015 Mar 10:1-24. [Epub ahead of print] PMID: 25752486.

Figure 4. Standard deviation and root-sum-square of phase delay and time-topeak in patients with and without myocardial scar
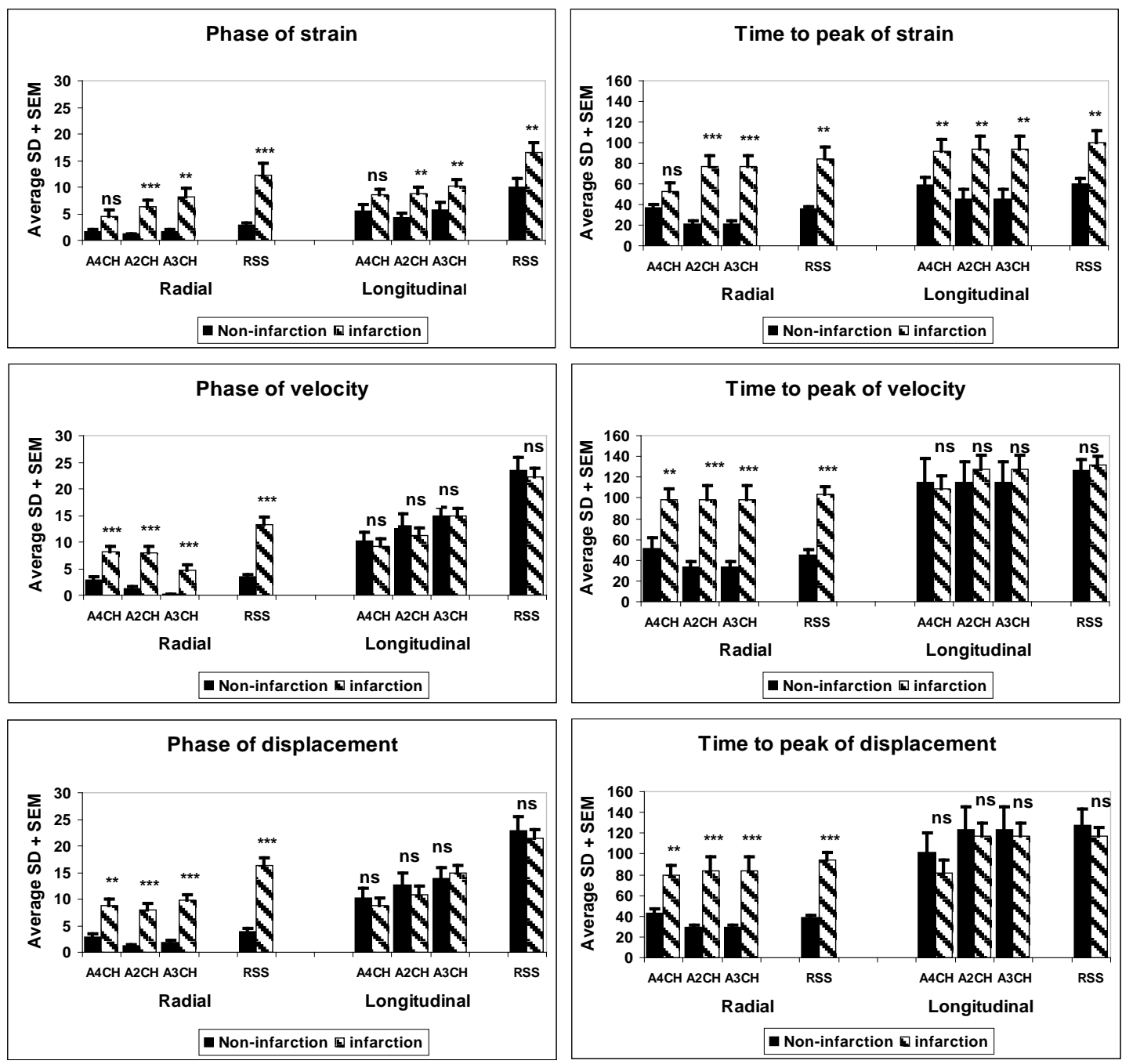
This is the pre peer-reviewed version of the following article, "Phase analysis detects heterogeneity of myocardial deformation on cine MRI", which in its final form has been published at Scand Cardiovasc J. 2015 Mar 10:1-24. [Epub ahead of print] PMID: 25752486.

Figure 5. Radial strain RSS-SD-phase $\%$ vs scar volume

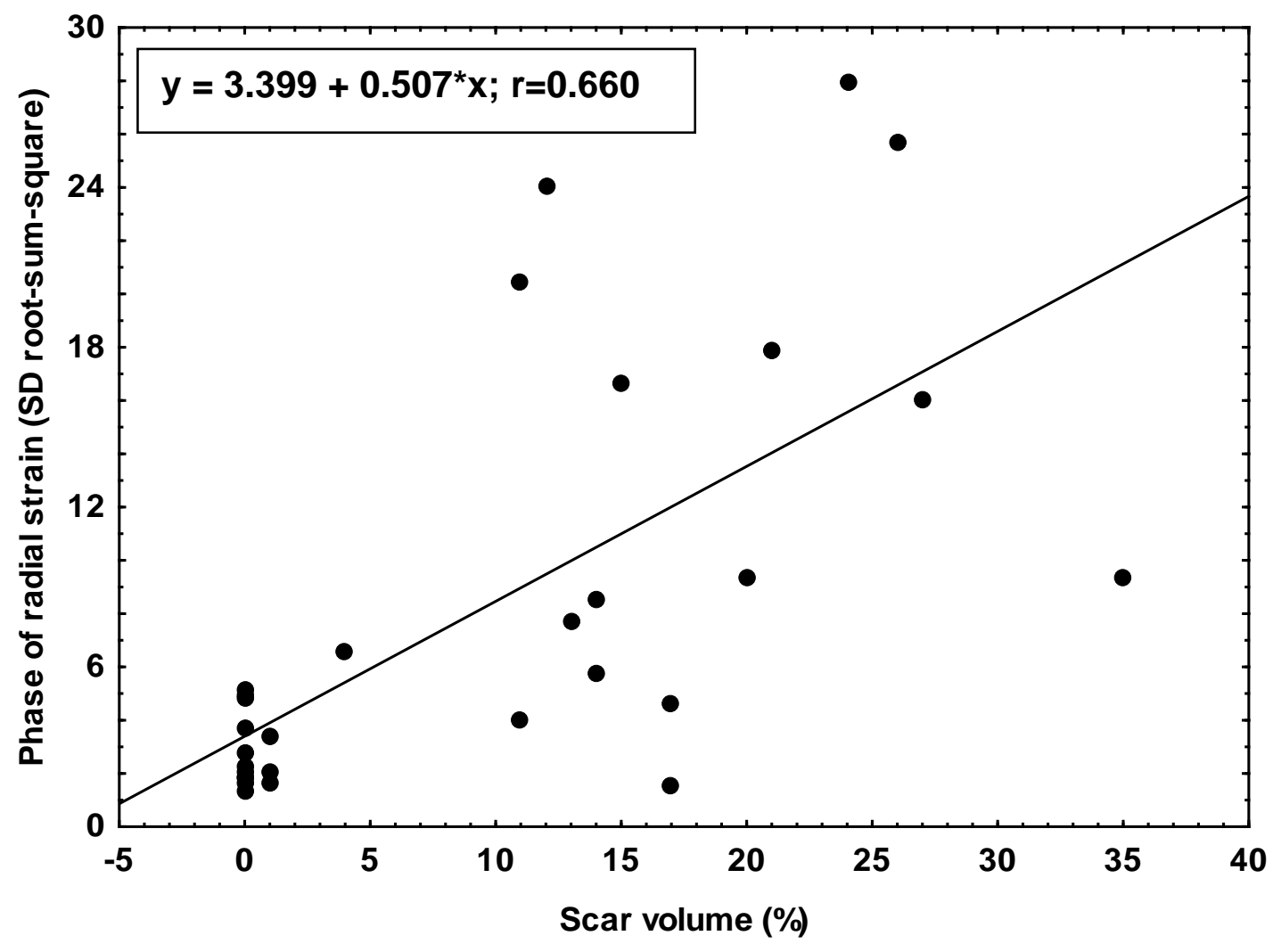


This is the pre peer-reviewed version of the following article, "Phase analysis detects heterogeneity of myocardial deformation on cine MRI", which in its final form has been published at Scand Cardiovasc J. 2015 Mar 10:1-24. [Epub ahead of print] PMID: 25752486.

Figure 6. Area-under-curve for the detection of scar

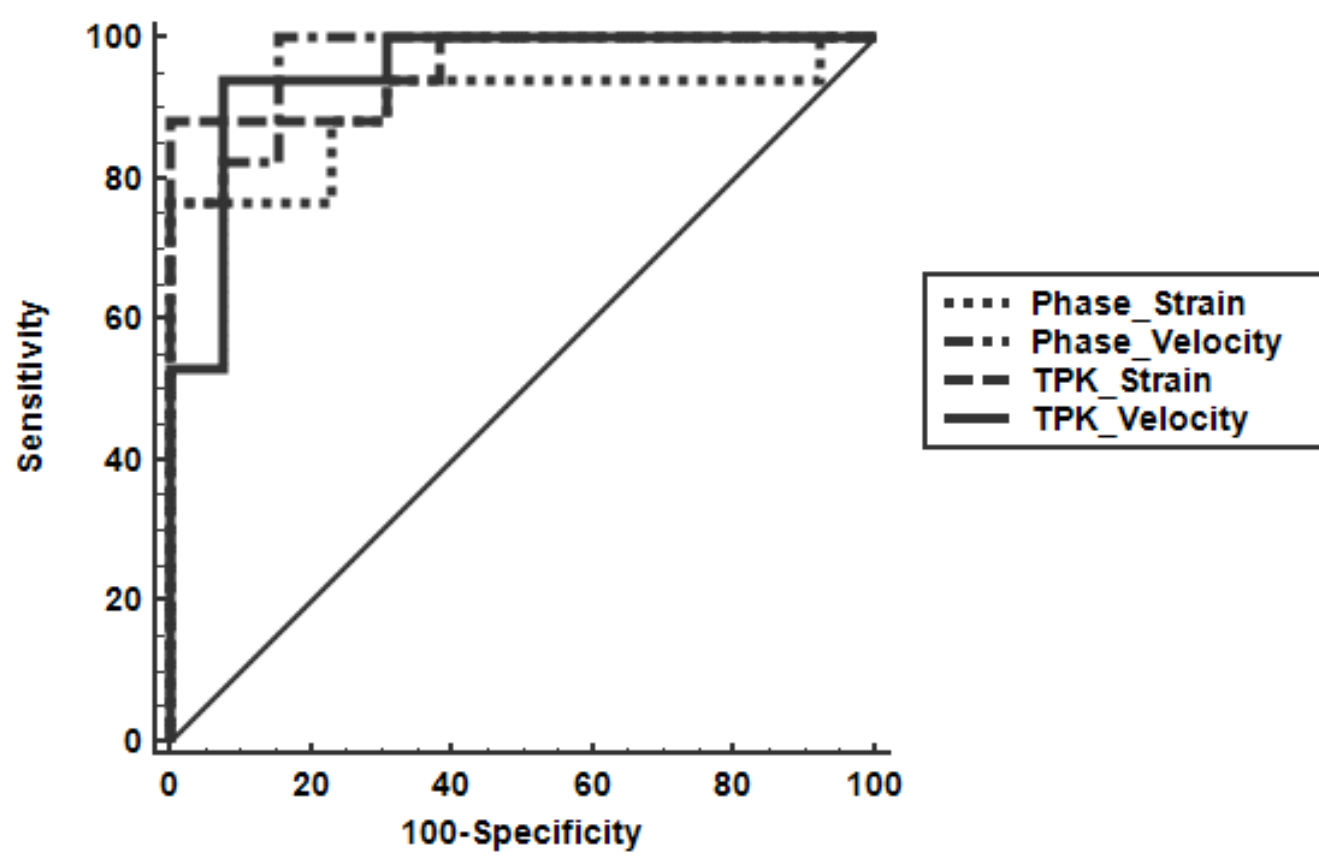


This is the pre peer-reviewed version of the following article, "Phase analysis detects heterogeneity of myocardial deformation on cine MRI", which in its final form has been published at Scand Cardiovasc J. 2015 Mar 10:1-24. [Epub ahead of print] PMID: 25752486.

Figure 7 Intra- and interobserver variability of phase\% from long-axis and short-axis segmentations
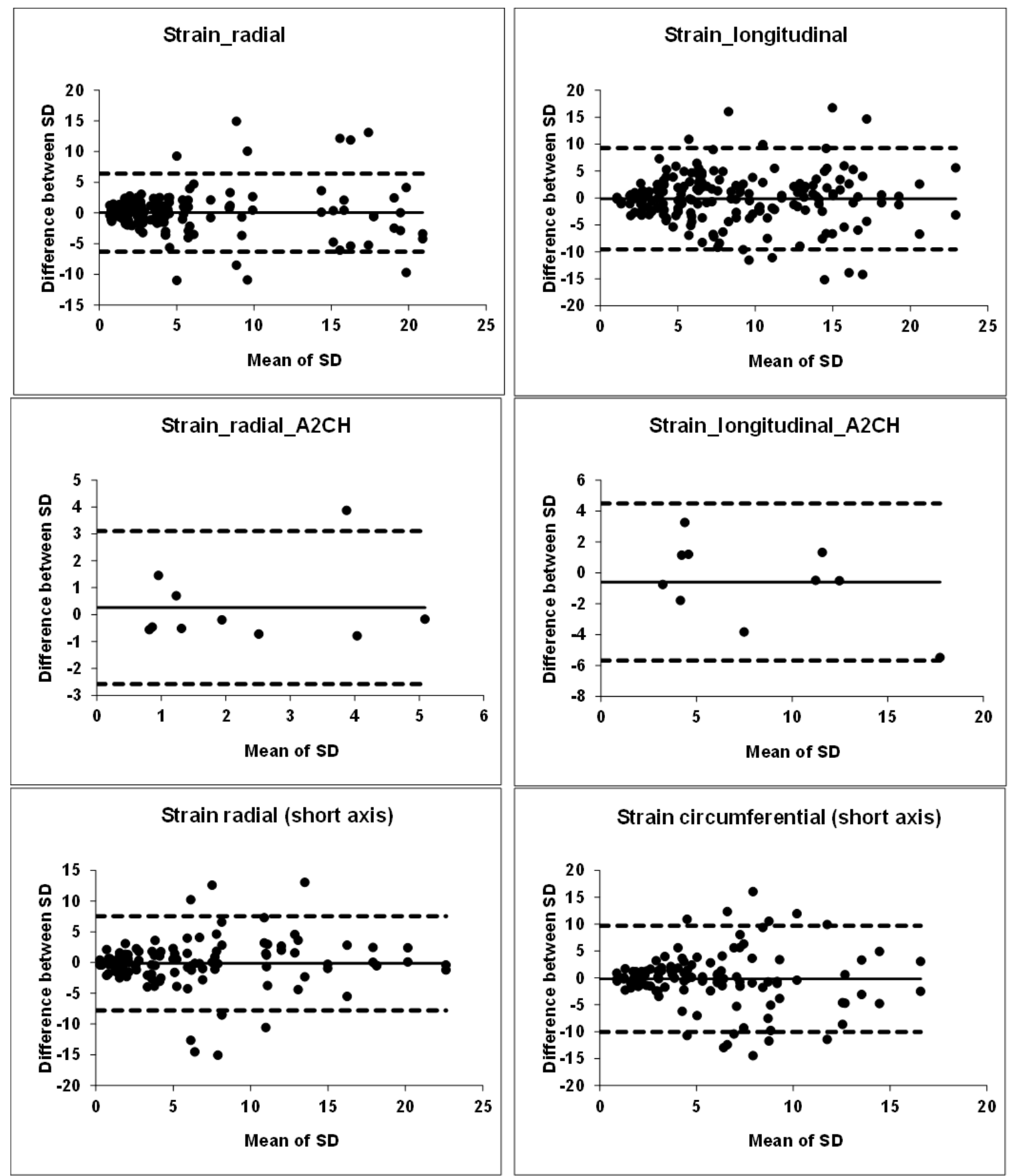
This is the pre peer-reviewed version of the following article, "Phase analysis detects heterogeneity of myocardial deformation on cine MRI", which in its final form has been published at Scand Cardiovasc J. 2015 Mar 10:1-24. [Epub ahead of print] PMID: 25752486. 